\title{
Synthesis of Polymers with Carbon-Carbon Chains by the Reaction of Xylylene Dihalides with Active Methylene Compounds Using the DBU Method
}

\author{
Tadatomi Nishikubo, ${ }^{*}$ Atsushi KameYama, and Kazuhiro OzaKı \\ Department of Applied Chemistry, Faculty of Engineering, \\ Kanagawa University, Rokkakubashi, Kanagawa-ku, Yokohama 221, Japan
}

(Received September 27, 1993)

\begin{abstract}
Some polymers with carbon-carbon chains were synthesized by reaction of $m$ - or p-xylylene dihalides with active methylene compounds such as malononitrile, methyl cyanoacetate, and dimethyl malonate using 1,8-diazabicyclo[5.4.0]undecene-7 (DBU) in aprotic polar solvents under relatively mild conditions. The viscosity of the resulting polymer increased with increasing monomer concentration and reaction temperature. However, the polymer was not obtained when the reaction was carried out using triethylamine, 1,5-diazabicyclo[4.3.0]nonene-5, or 1,4-diazabicyclo[2.2.2] octane.
\end{abstract}

KEY WORDS Synthesis / Polymer with Carbon-Carbon Chain / Xylylene Dihalides / Active Methylene Compounds / 1,8-Diazabicyclo[5.4.0]undecene-7 / Mild Reaction Condition /

Phase transfer catalysts are widely used for polymer synthesis ${ }^{1}$ and chemical modification of polymers ${ }^{2}$ containing pendant chloromethyl groups as well as for organic synthesis. ${ }^{3}$ The authors ${ }^{4}$ recently reported substitution reactions of poly(chloromethylstyrene) with active methylene compounds such as malononitrile and diethyl methylmalonate to give the corresponding polymers using quaternary onium salts or crown ethers as phase transfer catalysts (PTC)s. Imai and Ueda reported ${ }^{5-7}$ the synthesis of polymers with carbon-carbon chains by reaction of $p$-xylylene dichloride with $t$-butyl cyanoacetate and phenylacetonitrile (PAN) using PTCs. That is, PTC is a very simple and convenient for reaction between polymeric electrophile and low molecular weight (LMW) nucleophilic reagents. However, reaction between LMW electrophilic reagents and pendant nucleophiles such as carboxylate or phenol groups in polymers did not proceed in high conversion ${ }^{8,9}$ even in the presence of phase transfer catalysts.

The reaction of poly(methacrylic acid) or poly(4-hydroxystyrene) with alkyl halides such as propargyl bromide, nitrobenzyl bromide and 4-bromo-2-cyclohexanone proceeded very smoothly under mild conditions using 1,8diazabicyclo[5.4.0] undecene-7 (DBU) in aprotic polar solvents such as DMSO and DMF. We also reported ${ }^{13}$ the synthesis of polyesters by reaction of alkylene dihalides with dicarboxylic acids using DBU.

This paper reports the synthesis of polymers with carbon-carbon chains by reaction of xylylene dihalides with active methylene compounds using DBU in aprotic polar solvents as a promising application of DBU method for polymer synthesis.

\section{EXPERIMENTAL}

\section{Materials}

DBU, triethylamine (TEA), 1,5-diazabicy-

\footnotetext{
* To whom all correspondence should be addressed.
} 
clo[4.3.0]nonene-5 (DBN), 1,4-diazabicyclo[2.2.2] octane (DABCO), PAN, methyl cyanoacetate (MCA), malononitrile (MN), and dimethyl malonate (DMM) were used after distillation using $\mathrm{CaH}_{2} \cdot m$-Xylylene dichloride (MXDC) and 1,4-diiodobutane (DIB) were purified by distillation before use. $p$-Xylylene dichloride (PXDC) was recrystallized from acetone before use. Reagent grade benzyl bromide (BzBr) was used without further purification. $m$-Xylylene dibromide (MXDB) and $p$-xylylene dibromide (PXDB) were prepared by reaction of the corresponding xylenes with $\mathrm{N}$-bromosuccinimide according to the method reported previously. ${ }^{14}$

\section{Apparatus}

GLC analysis was carried out on a Shimadzu Model GC-9AM gas chromatograph with a $3 \mathrm{~mm} \times 2.6 \mathrm{~m}$ column packed with $3 \%$ Silicon OV-101 on Shimalite W (AW-DMCS). IR spectra were measured on a JASCO Model IR-700 spectrophotometer. ${ }^{1} \mathrm{H}$ NMR spectra were recorded on a JEOL Model JNM EX-90 $(90 \mathrm{MHz})$ instrument in $\mathrm{CDCl}_{3}$ with $\mathrm{Me}_{4} \mathrm{Si}$ as the internal standard.

\section{Typical Procedure for Model Reaction of Benzyl}

Bromide with Methyl Cyanoacetate Using $D B U$

$\mathrm{BzBr}[3.421 \mathrm{~g}(20 \mathrm{mmol})]$ dissolved in $3 \mathrm{ml}$ of DMF and $3.045 \mathrm{~g}(20 \mathrm{mmol})$ of DBU dissolved in $2 \mathrm{ml}$ of DMF were dripped separately into the DMF solution $(5 \mathrm{ml})$ of $0.991 \mathrm{~g}(10 \mathrm{mmol})$ of MCA kept at $30^{\circ} \mathrm{C}$ for $1 \mathrm{~h}$, after which the reaction was allowed to continue for another $3 \mathrm{~h}$ at $30^{\circ} \mathrm{C}$. The degree of conversion of $\mathrm{BzBr}$ was $90 \%$, as determined by GLC analysis. The reaction mixture was poured into water, and the precipitated product was filtered, washed with water, and dried. The crude product was recrystallized twice from methanol. Yield of methyl $\alpha, \alpha^{\prime}$-dibenzylcyanoacetate (1) was $75 \%$. mp $79.5-80.5^{\circ} \mathrm{C}$. IR $(\mathrm{KBr}): 2242(\mathrm{C} \equiv \mathrm{N}), \quad 1734 \quad(\mathrm{C}=\mathrm{O})$, and $1234 \mathrm{~cm}^{-1}$ (C-O-C). ${ }^{1} \mathrm{H}$ NMR $\left(\mathrm{CDCl}_{3}\right)$ : $\delta=3.15\left(2 \mathrm{H}, \mathrm{d}, J=13.4 \mathrm{~Hz}, \mathrm{CH}_{2}\right), 3.42(2 \mathrm{H}$, $\left.\mathrm{d}, J=13.4 \mathrm{~Hz}, \mathrm{CH}_{2}\right), 3.52\left(3 \mathrm{H}, \mathrm{s}, \mathrm{CH}_{3}\right)$, and $7.37 \mathrm{ppm}(10 \mathrm{H}, \mathrm{s}, \mathrm{Ar}-\mathrm{H})$.

Anal. Calcd for $\mathrm{C}_{18} \mathrm{H}_{17} \mathrm{NO}_{2}: \mathrm{C}, 77.40 \% ; \mathrm{H}$, $6.13 \% ; \mathrm{N}, 5.01 \%$. Found: $\mathrm{C}, 77.70 \% ; \mathrm{H}$, $6.43 \% ; \mathrm{N}, 4.95 \%$.

Typical Procedure for the Reaction of Xylylene Dihalide with Active Methylene Compound Using $D B U$

To the DMF solution $(1 \mathrm{ml})$ of $0.495 \mathrm{~g}$ ( $5 \mathrm{mmol})$ of MCA, $1.320 \mathrm{~g}(5 \mathrm{mmol})$ of MXDB dissolved in $2.5 \mathrm{ml}$ of DMF and $1.522 \mathrm{~g}$ $(10 \mathrm{mmol})$ of DBU dissolved in $1 \mathrm{ml}$ of DMF were dripped separately at $30^{\circ} \mathrm{C}$ for $1 \mathrm{~h}$. The reaction mixture was stirred at $30^{\circ} \mathrm{C}$ for $3 \mathrm{~h}$, and poured into $150 \mathrm{ml}$ of methanol. The resulting polymer (3) was purified by reprecipitating twice from dichloromethane solution into methanol, and drying at $60^{\circ} \mathrm{C}$ in vacuo. The yield of polymer 3 was $78 \%$. Reduced viscosity, $0.26 \mathrm{dl} \mathrm{g}^{-1}\left(0.5 \mathrm{gdl}^{-1}\right.$ in DMF at $\left.30^{\circ} \mathrm{C}\right)$. IR (film): $2244(\mathrm{C} \equiv \mathrm{N}), 1744(\mathrm{C}=\mathrm{O})$, and $1234 \mathrm{~cm}^{-1}(\mathrm{C}-\mathrm{O}-\mathrm{C}) .{ }^{1} \mathrm{H}$ NMR $\left(\mathrm{CDCl}_{3}\right)$ : $\delta=3.06\left(2 \mathrm{H}, \mathrm{d}, J=13.4 \mathrm{~Hz}, \mathrm{CH}_{2}\right), 3.33(2 \mathrm{H}$, $\left.\mathrm{d}, J=13.4 \mathrm{~Hz}, \mathrm{CH}_{2}\right), 3.54\left(3 \mathrm{H}, \mathrm{s}, \mathrm{CH}_{3}\right)$, and $7.23 \mathrm{ppm}(4 \mathrm{H}, \mathrm{s}, \mathrm{Ar}-\mathrm{H})$.

\section{RESULTS AND DISCUSSION}

Model reactions of $\mathrm{BzBr}$ with $\mathrm{MCA}$ and $\mathrm{MN}$ were carried out using DBU in DMF at $30^{\circ} \mathrm{C}$ (Scheme 1). The reactions proceeded very smoothly to give the corresponding methyl $\alpha, \alpha^{\prime}$-dibenzylcyanoacetate (1) and $\alpha, \alpha^{\prime}$-dibenzylmalononitrile ${ }^{15}$ (2) in 90 and $100 \%$ yields, respectively, under mild conditions. These results suggest high-yield reactions of the alkyl halide with MCA and MN using DBU as a base may be applicable to the synthesis of condensation polymers with carbon-carbon chain.

Since the model reactions of $\mathrm{BzBr}$ with active methylene compounds proceeded very smoothly using $\mathrm{DBU}$ at $30^{\circ} \mathrm{C}$ in $\mathrm{DMF}$, the reaction of MXDB with MCA was carried out in the 


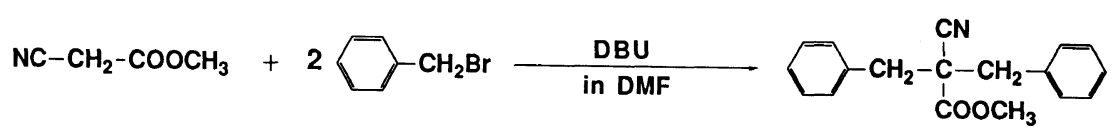

(1)

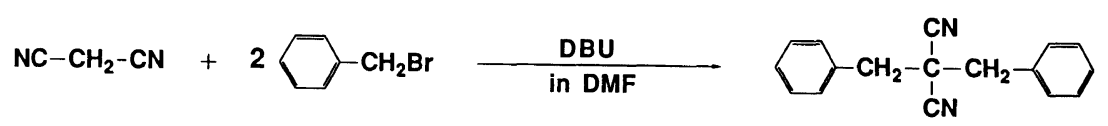

(2)

Scheme 1.

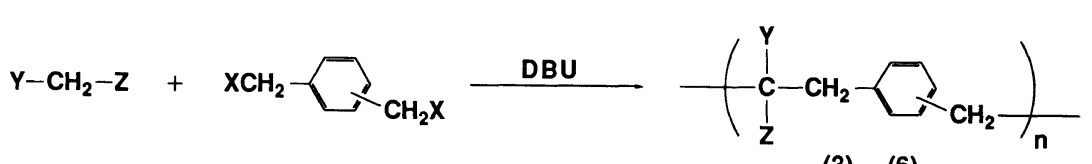

(3) - (6)

\begin{tabular}{|c|c|c|}
\hline $\begin{array}{c}\text { Active } \\
\text { methylene }\end{array}$ & $\mathbf{Y}$ & $\mathbf{z}$ \\
\hline MCA & $-\mathrm{CN}$ & $-\mathrm{COOCH}_{3}$ \\
\hline MN & $-\mathrm{CN}$ & $-\mathrm{CN}$ \\
\hline DMN & $-\mathrm{COOCH}_{3}$ & $-\mathrm{COOCH}_{3}$ \\
\hline PAN & $-\mathrm{CN}$ & $-P h$ \\
\hline
\end{tabular}

\begin{tabular}{c|c}
$\begin{array}{l}\text { Xylylene } \\
\text { dihalide }\end{array}$ & $\mathbf{X}$ \\
\hline MXDB & Br \\
PXDB & Br \\
MXDC & CI \\
PXDC & CI
\end{tabular}

Scheme 2.

Table I. Effects of reaction solvent on the polycondensation of MXDB with MCA using DBU ${ }^{\mathrm{a}}$

\begin{tabular}{ccccc}
\hline \multirow{2}{*}{$\begin{array}{c}\text { Run } \\
\text { No. }\end{array}$} & $\begin{array}{c}\text { Reaction } \\
\text { solvent }\end{array}$ & Yield $^{\mathrm{b}}$ & & $\eta_{\text {red }}^{\mathrm{c}}$ \\
\cline { 3 - 3 } & & $\%$ & & $\mathrm{dl} \mathrm{g}^{-1}$ \\
\hline 1 & Anisole & 58 & 0.15 \\
3 & DMF & 78 & 0.26 \\
4 & DMAc & 75 & 0.19 \\
5 & NMP & 66 & 0.16 \\
6 & DMSO & 77 & 0.24 \\
& HMPA & 66 & 0.21
\end{tabular}

a Reaction was carried out with $5 \mathrm{mmol}$ of MCA and $5 \mathrm{mmol}$ of MXDB using $10 \mathrm{mmol}$ of DBU in $5 \mathrm{ml}$ of solvent at $30^{\circ} \mathrm{C}$ for $3 \mathrm{~h}$.

b Methanol insoluble part.

c Measured at $0.5 \mathrm{~g} \mathrm{dl}^{-1}$ in DMF at $30^{\circ} \mathrm{C}$.

presence of equivalent amounts of DBU in various solvents at $30^{\circ} \mathrm{C}$. As summarized in Table I, the corresponding polymer (3) with reduced viscosity of about 0.25 was prepared when the reaction was carried out in DMF or DMSO. Polymer 3 with reduced viscosities of
$0.16-0.21$ was obtained using anisole, DMAc, NMP and HMPA as solvents under the same conditions (Table I). This indicates that DMF and DMSO are suitable solvents to obtain the polymer with carbon-carbon chains by reaction of xylylene dihalide with active methylene compound.

The reaction of MXDB with MCA was also examined using various bases. The polymer was not obtained when other organic bases such as DBN, TEA ( $\left.K_{\mathrm{a}}=10.8\right)$, or DABCO $\left(\mathrm{p} K_{\mathrm{a}}=8.7\right)$ were used. This means that DBU $\left(\mathrm{p} K_{\mathrm{a}}=11.5\right.$ ) is an excellent organic base for the synthesis of polymers with carbon-carbon chains by reaction of alkylene dihalide with an active methylene compound, because DBU has higher $\mathrm{p} K_{\mathrm{a}}$ than other organic bases.

Reactions of MCA with MXDB or PXDC were conducted at various monomer concentrations at $30^{\circ} \mathrm{C}$ for $3 \mathrm{~h}$. As shown in Figure 1 , inherent viscosities of the corresponding polymers 3 and 4 increased with monomer concentration in each reaction. These results 


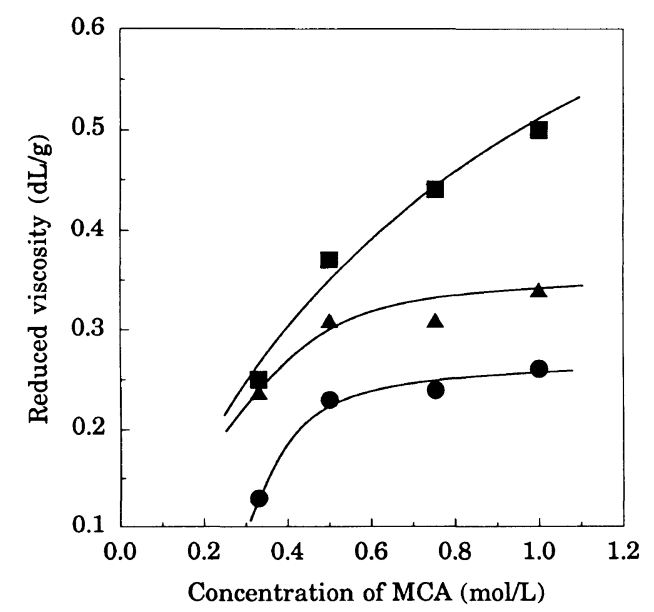

Figure 1. Effects of monomer concentration on reaction of alkylene dihalide with MCA using DBU in DMF at $30^{\circ} \mathrm{C}$ for 3h: ( $)$, with $\operatorname{MDXB}$; $(\mathbf{A})$, with PXDC; $(\boldsymbol{\square})$, with PXDC at $60^{\circ} \mathrm{C}$.

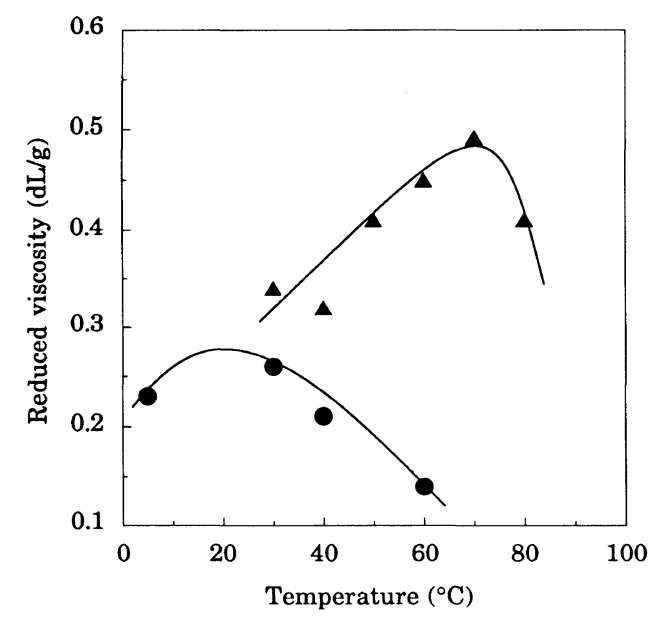

Figure 2. Effects of temperature on reaction of alkylene dihalide ( $5 \mathrm{mmol})$ with MCA $(5 \mathrm{mmol})$ using DBU (10 mmol) in DMF (5 ml) for $3 \mathrm{~h}$ : (O), with $\mathrm{MXDB} ;(\boldsymbol{\Delta})$ with PXDC.

show that polymer 4 prepared by the reaction with PXDC has higher viscosity than polymer 3 obtained by reaction with MXDB at the same monomer concentration, though the reactivity of PXDC was thought to be lower than MXDB. Reaction with PXDC was also carried out at $60^{\circ} \mathrm{C}$ for $3 \mathrm{~h}$ in DMF, and polymer 4 with higher viscosity was obtained.

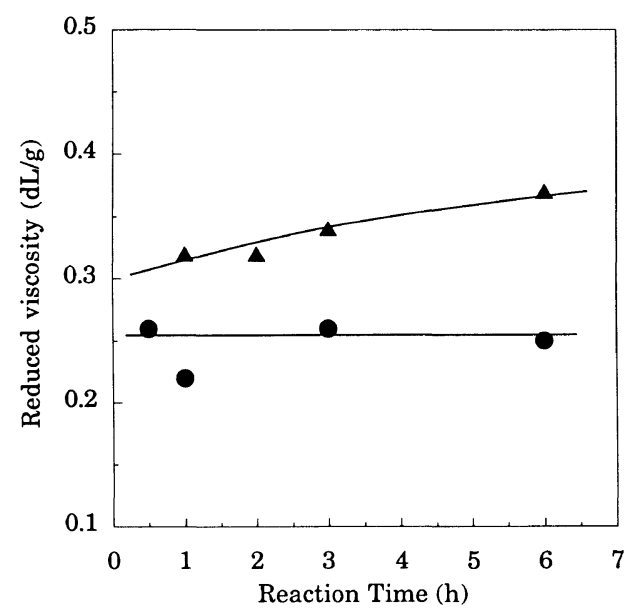

Figure 3. Effects of time on reaction of alkylene dihalide (5 mmol) with MCA $(5 \mathrm{mmol})$ using DBU $(10 \mathrm{mmol})$ in $\operatorname{DMF}(5 \mathrm{ml})$ at $30^{\circ} \mathrm{C}:(\mathbf{O})$, with MXDB; (A), with PXDC.

The effect of temperature on the reaction of MCA with MXDB and PXDC in DMF for $3 \mathrm{~h}$ was examined. As shown in Figure 2, polymer 3 with the highest viscosity was obtained by reaction with MXDB at $30^{\circ} \mathrm{C}$. Polymer 4 with the highest viscosity was obtained, when reaction with PXDC was carried out at $70^{\circ} \mathrm{C}$. It seems that the oxidation of the bromomethyl group ${ }^{16}$ in MXDB occurs as a side reaction in this reaction, as well as in the reaction of dicarboxylic acid with MXDB using DBU-DMF at higher temperatures, ${ }^{13}$ because MXDB has higher reactivity than PXDC. These results also demonstrated that reaction with PXDC produces the corresponding polymer 4 with higher viscosity than reaction with MDXB under the same conditions.

Correlations between viscosities of the resulting polymers and reaction times are shown in Figure 3. The viscosity of polymer 3 was independent of the reaction time, when reaction with MXDB was carried out at $30^{\circ} \mathrm{C}$. The viscosity of polymer 4 increased slightly with time, when reaction with PXDC was carried out under the same conditions. This means that reactions of MCA with MXDB and PXDC proceed very smoothly for a short 
Table II. Reactions of various active methylene compounds with alkylene dihalides using the DBU method ${ }^{\mathbf{a}}$

\begin{tabular}{|c|c|c|c|c|c|}
\hline $\begin{array}{l}\text { Run } \\
\text { No. }\end{array}$ & $\begin{array}{l}\text { Methylene } \\
\text { comp. } \\
\left(\mathrm{p} K_{\mathrm{a}}\right)\end{array}$ & $\begin{array}{l}\text { Alkylene } \\
\text { dihalide }\end{array}$ & $\begin{array}{c}\text { Polym. } \\
\text { no. }\end{array}$ & $\frac{\text { Yield }^{\mathrm{b}}}{\%}$ & $\frac{\eta_{\text {red }} \mathrm{c}}{\mathrm{dl} \mathrm{g}^{-1}}$ \\
\hline 2 & MCA (9) & MXDB & 3 & 78 & 0.26 \\
\hline 10 & MCA & MXDC & 3 & 77 & 0.21 \\
\hline 11 & $\mathrm{MCA}^{\mathrm{d}}$ & PXDB & 4 & 89 & $0.43^{\mathrm{e}}$ \\
\hline 12 & $\mathrm{MCA}$ & PXDC & 4 & 66 & $0.34^{\mathrm{e}}$ \\
\hline 13 & MCA & DIB & - & 0 & - \\
\hline 14 & $\mathrm{MCA}^{\mathrm{f}}$ & DIB & - & 0 & - \\
\hline 15 & $\mathrm{MN}(11)$ & MXDB & 5 & 81 & 0.23 \\
\hline 16 & DMM (13) & MXDB & 6 & 54 & 0.03 \\
\hline 17 & PAN (19) & MXDB & - & 0 & - \\
\hline
\end{tabular}

a Reaction was carried out with $5 \mathrm{mmol}$ of each monomer using $10 \mathrm{mmol}$ of DBU in $5 \mathrm{ml}$ of DMF.

b Methanol insoluble part.

c Measured at $0.5 \mathrm{gd} \mathrm{l}^{-1}$ in DMF at $30^{\circ} \mathrm{C}$.

d $20 \mathrm{ml}$ of DMF was used.

e Measured at $0.5 \mathrm{gd} \mathrm{l}^{-1}$ in $\mathrm{m}$-cresol at $30^{\circ} \mathrm{C}$.

f Reaction was carried out at $60^{\circ} \mathrm{C}$.

Table III. IR and ${ }^{1} \mathrm{H}$ NMR spectral data of the polymers

\begin{tabular}{|c|c|c|}
\hline \multirow{2}{*}{$\begin{array}{l}\text { Polym. } \\
\text { no. }\end{array}$} & $\mathrm{IR}^{\mathrm{a}}$ & ${ }^{1} \mathrm{H} \mathrm{NMR}^{\mathrm{b}}$ \\
\hline & $\mathrm{cm}^{-1}$ & ppm \\
\hline 3 & $\begin{array}{l}2244(\mathrm{C} \equiv \mathrm{N}) \\
1744(\mathrm{C}=\mathrm{O}) \\
1234(\mathrm{C}-\mathrm{O}-\mathrm{C})\end{array}$ & $\begin{array}{l}3.06\left(2 \mathrm{H}, \mathrm{d}, J=13.4 \mathrm{~Hz}, \mathrm{CH}_{2}\right), \\
3.33\left(2 \mathrm{H}, \mathrm{d}, J=13.4 \mathrm{~Hz}, \mathrm{CH}_{2}\right), \\
3.54\left(3 \mathrm{H}, \mathrm{s}, \mathrm{CH}_{3}\right), \\
7.23(4 \mathrm{H}, \mathrm{s}, \mathrm{Ar}-\mathrm{H})\end{array}$ \\
\hline 4 & $\begin{array}{l}2242(\mathrm{C} \equiv \mathrm{N}) \\
1744(\mathrm{C}=\mathrm{O}) \\
1234(\mathrm{C}-\mathrm{O}-\mathrm{C})\end{array}$ & $\begin{array}{l}3.07\left(2 \mathrm{H}, \mathrm{d}, J=13.2 \mathrm{~Hz}, \mathrm{CH}_{2}\right), \\
3.30\left(2 \mathrm{H}, \mathrm{d}, J=12.7 \mathrm{~Hz}, \mathrm{CH}_{2}\right), \\
3.40-3.62\left(3 \mathrm{H}, \mathrm{br} \mathrm{s}, \mathrm{CH}_{3}\right), \\
7.24(4 \mathrm{H}, \mathrm{s}, \mathrm{Ar}-\mathrm{H}) .\end{array}$ \\
\hline 5 & $2248(\mathrm{C} \equiv \mathrm{N})$ & $\begin{array}{l}3.15-4.05\left(4 \mathrm{H}, \mathrm{brs}, \mathrm{CH}_{2}\right) \\
7.46(4 \mathrm{H}, \mathrm{s}, \mathrm{Ar}-\mathrm{H})\end{array}$ \\
\hline
\end{tabular}

${ }^{\text {a }}$ Measured on KRS plate.

b Measured in $\mathrm{CDCl}_{3}$.

reaction time using $\mathrm{DBU}$ under mild conditions, and PXDC is a more suitable monomer for this polymerization.

The reactions of some active methylene compounds such as MCA, MN, DMM, and PAN with alkylene dihalides such as MXDB, MXDC, PXDB, PXDC, DIB were performed using DBU in DMF at $30^{\circ} \mathrm{C}$ for $5 \mathrm{~h}$ (Table III). IR and ${ }^{1} \mathrm{H}$ NMR spectral data of typical resulting polymers are summarized in Table
IV. Each reaction of MCA with xylylene dihalides proceeded very smoothly to give the corresponding polymers 3 and $\mathbf{4}$. However, reaction of MCA with DIB did not proceed even at $60^{\circ} \mathrm{C}$, because the reactivity of DIB was much lower than that of the above xylylene dihalides.

Polymer 5 with reduced viscosity of 0.23 was obtained in good yield by reaction of $\mathrm{MN}$ with MXDB using DBU. However, the yield and viscosity of polymer 6 obtained by the reaction of DMM with MXDB were very low. The ${ }^{1} \mathrm{H}$ NMR spectrum of polymer 6 with low viscosity showed additional proton signals due to the DBU residue and $-\mathrm{CH}_{2}-$ of the benzylammonium group at $1.50-2.38$ and $4.84 \mathrm{ppm}$, respectively. This means that an addition reaction between the terminal bromomethyl group in the polymer chain or in the MXDB and the DBU occurs as a side reaction during the reaction of MXDB with DMM using DBU.

The reaction of PAN with PXDC using inorganic base such as $\mathrm{KOH}$ and $\mathrm{NaOH}$ in the presence of phase transfer catalysts proceeds very smoothly to give the corresponding polymer. However, the reaction of PAN with MXDB did not occur in the presence of DBU 
in $\mathrm{DMF}$ at $30^{\circ} \mathrm{C}$.

From the above results, it is concluded that corresponding polymers with carbon-carbon chains are synthesized by reactions between xylylene dihalides and active methylene compounds with $\mathrm{p} K_{\mathrm{a}}$ below 11 using the DBU method under mild reaction conditions. However, similar polymers with carbon-carbon chain could not be synthesized by reaction between xylylene dihalides and active methylene compounds with $\mathrm{p} K_{\mathrm{a}}$ above 13 using the DBU method. That is, the production of polymers with high viscosity by the above reaction is strongly affected by $\mathrm{p} K_{\mathrm{a}}$ of the active methylene compounds and $\mathrm{p} K_{\mathrm{a}}$ of the base used.

\section{REFERENCES}

1. For example, a) Y. Imai, J. Syn. Org. Chem., Jpn., 42, 1095 (1984); b) L. F. Matias and C. E. Carraher, Jr., Ed., "Crown Ether and Phase Transfer Catalysis in Polymer Science," Plenum Press, New York, N.Y., 1984.

2. For example, a) T. Nishikubo, Kobunshi, 35, 132 (1986); b) T. Nishikubo and T. Iizawa, J. Syn. Org.
Chem., Jpn., 51, 157 (1993).

3. For example, C. M. Starks and C. Liotta, "Phase Transfer Catalysis," Academic Press, New York, N.Y., 1978.

4. T. Nishikubo, T. Iizawa, and K. Kobayashi, Makromol. Chem. Rapid Commun., 2, 387 (1981).

5. Y. Imai, T-Q, Nguyen, and M. Ueda, J. Polym. Sci., Polym. Lett. Ed., 19, 205 (1981).

6. Y. Imai, A. Kameyama, T-Q, Nguyen, and M. Ueda, J. Polym. Sci., Polym. Chem. Ed., 19, 2997 (1981).

7. M. Ueda and K. Sato, Kobunshi Ronbunshu, 41, 121 (1984).

8. T. Shimokawa and T. Nishikubo, Kobunshi Ronbunshu, 43, 901 (1986).

9. S. H. Chen and Y. F. Maa, Macromolecules, 21, 904 (1988).

10. T. Shimokawa and T. Nishikubo, Kobunshi Ronbunshu, 44, 641 (1987)

11. T. Nishikubo, T. Iizawa, A. Takahashi, and T. Shimokawa, J. Polym. Sci., Polym. Chem. Ed., 28, 105 (1990).

12. T. Iizawa, K. Nishiyama, and T. Nishikubo, J. Polym. Sci., Part A: Polym. Chem., 31, 443 (1993).

13. T. Nishikubo and K. Ozaki, Polym. J., 22, 1043 (1990).

14. T. Iizawa, H. Kudou, and T. Nishikubo, J. Polym. Sci., Part A; Polym. Chem., 29, 1875 (1991).

15. Y. Hori, Y. Nagano, K. Tanaka, and H. Taniguchi, Chem. Express, 1, 491 (1986).

16. J. A. Moore and J. J. Kennedy, J. Macromol. Sci.-Chem., A13, 461 (1979). 